\title{
Probability learning and the blank trials law
}

\author{
Martin L. Richter and Marvin Levine \\ INDIANA UNIVERSITY
}

\begin{abstract}
This experiment supported and generalized a theorem relating outcome and nonoutcome performance derived from a hypothesis model for 2-choice discrimination learning in adult human Ss. The verified prediction was that Ss behave the same when $\mathrm{E}$ says nothing as when $E$ says "right" to every response. This conclusion holds even for sequences of 20 responses and for probability learning tasks.
\end{abstract}

\section{Introduction}

A recent series of discrimination-learning experiments (Levine, Leitenberg, \& Richter, 1964) were devoted to studying the choice behavior of adult human Ss during "blank" (or "nonoutcome") trials. Four experiments (two-trials-per-problem-learning set, modified double alternation, contingent discrimination, and a guessing problem) were performed with this common feature: the E presented outcomes (said "right" or "wrong" after each response) during most of the problem. However, a series of test trials was periodically presented during which the E said either nothing (the nonoutcome series) or "right" to every response.

In all four experiments the pattern of choices during the nonoutcome series was virtually identical to the pattern during the "right" series. This general result supported a theorem proposed by Levine (1963): "During a nonoutcome series the $\mathrm{S}$ behaves as though the $\mathrm{E}$ were saying 'right'."

The test series in the four experiments were relatively short. The longest lasted 10 trials. The present experiment was an attempt to generalize the theorem and to determine, in particular, whether any differential drift or other cumulative effects could be observed with a longer test series. Accordingly, a test series of 20 trials was used. The experiment also attempted to generalize the theorem to the area of probability learning.

\section{Method}

The materials for a problem consisted of a set of $513 \times 5$ index cards. With the exception of the 31st card, which was plain, every card had typed on it the same two CVC nonsense syllables. These were always typed 2 in apart on the center line.

The Ss were 88 paid volunteers from the Indiana University student body. Just previous to this experiment all Ss had been run in a four-trial-per-problem multidimensional learning-set experiment.

Each $\mathrm{S}$ received two problems, each of which was divided into a training series of 30 outcome trials followed by a 20 trial test series. During the training series one of the syllables was called right more frequently than the other with one of two different

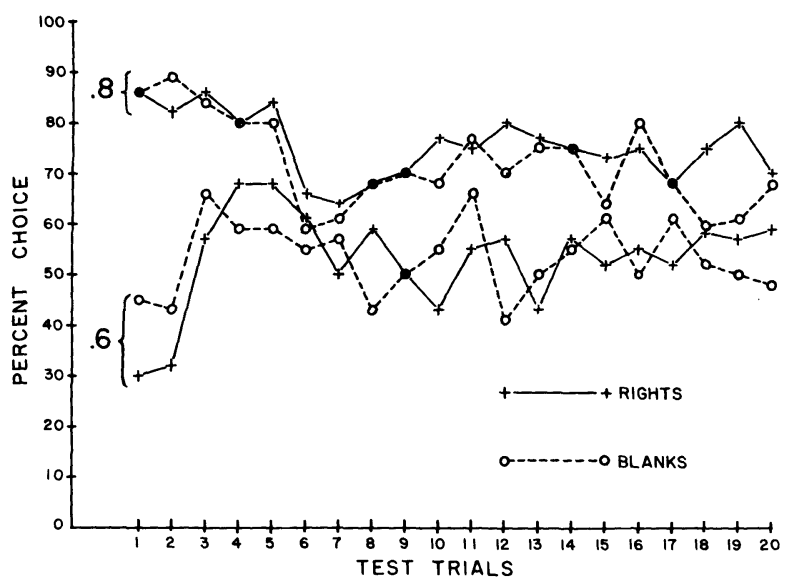

Fig. 1. Percent choice during the test series of the syllable more frequently reinforced in training.

probabilities. For half the Ss on problem 1 the probability was .8 , for the other half. .6. The sequence of the correct syllable was random but the same for all Ss. During the test series, the two groups were subdivided, half receiving blanks (E said nothing), the other half rights (E said "right" each time regardless of S's choice). At the outset of the test series the Ss were instructed that the remaining trials were critical ones and that $\mathrm{E}$ wanted to see how many they could get right. Those Ss getting blanks were further informed that $\mathrm{E}$ would not be saying anything. Following the test series of problem 1 the Ss were reinstructed for problem 2 . Problem 2 was a replication of problem 1 with the following changes: (1) different syllables were used, (2) the other probability was used in the training series, (i.e., the $\mathrm{S}$ went from a .8 training series to .6, and vice versa) and (3) in the test series, Ss who had blanks on problem 1 had rights on problem 2 , and vice versa. Details of the procedure and instructions may be obtained from Experiment IV of Levine et al (1964).

\section{Results and Diseussion}

Problems 1 and 2 yielded similar results and are combined in Fig. 1 which depicts the percent choice during the test series of the syllable more frequently reinforced in training. The patterns of choice over the 20 test trials for rights and blanks are clearly alike. Despite the relatively long test series there is no upward drift in the rights groups and no drifting apart of the rights and blanks curves. Chi-square tests on individual trials indicate no significant difference at or beyond the .05 level. The means for rights and blanks over all 20 test trials are quite close (see Table 1), and the differences are not statistically reliable. 
Table 1. Mean percent choice of the more frequently reinforced syllable over all 20 test trials

Training series

Test

$\begin{array}{lcc}\text { series } & .60 & .80 \\ \text { Rights } & 53.2 & 75.6 \\ \text { Blanks } & 53.3 & 72.2\end{array}$

The results of this experiment lend further support and greater generality to the theorem relating rights and nonoutcome performance and to a general hypothesis model. The relevant assumptions from such a model are: (1) what is directly affected by the outcome procedure, rights and blanks in this case, is the S's hypothe- sis, defined as a mediating process manifested in a particular response sequence; (2) neither rights nor blanks lead the $\mathrm{S}$ to change this hypothesis. Under these two outcome procedures, therefore, identical responses should be produced. The presented experiment shows that this conclusion holds even for sequences of 20 responses and for a fifth kind of discrimination problem, that of probability learning.

\section{References}

LEVINE, M. Mediating processes in humans at the outset of discrimination learning. Psychol. Rev., 1963, 70, 254-276.

LEVINE, M., LEITENBERG, H., \& RICHTER, M. L. The blank trials law: the equivalence of positive reinforcement and nonreinforcement. Psychol. Rev., 1964, 71, 94-103.

\section{Note}

1. This study was supported in part by a Public Health Service fellowship held by the first author and in part by Public Health Service Research Grant MH 08485-01. 